\title{
Impact of cavitron ultrasonic surgical aspirator (CUSA) and bipolar radiofrequency device (Habib-4X) based hepatectomy for hepatocellular carcinoma on tumour recurrence and disease- free survival
}

\author{
Kai-Wen Huang ${ }^{1,2,3}$, Po-Huang Lee ${ }^{1}$, Tomokazu Kusano ${ }^{4}$, Isabella Reccia ${ }^{4}$, Kumar \\ Jayant ${ }^{4}$ and Nagy Habib ${ }^{4}$ \\ ${ }^{1}$ Department of Surgery \& Hepatitis Research Center, National Taiwan University Hospital, Taipei, Taiwan \\ ${ }^{2}$ Centre of Mini-invasive Interventional Oncology, National Taiwan University Hospital, Taipei, Taiwan \\ ${ }^{3}$ Graduate Institute of Clinical Medicine, College of Medicine, National Taiwan University, Taipei, Taiwan \\ ${ }^{4}$ Department of Surgery and Cancer, Imperial College London, London, UK \\ Correspondence to: Kumar Jayant, email: jkumar@ic.ac.uk
}

Keywords: hepatocellular cancer, liver resection

Received: March 14, $2017 \quad$ Accepted: September 08, $2017 \quad$ Published: September 26, 2017

Copyright: Huang et al. This is an open-access article distributed under the terms of the Creative Commons Attribution License 3.0 (CC BY 3.0), which permits unrestricted use, distribution, and reproduction in any medium, provided the original author and source are credited.

\section{ABSTRACT}

Background: The aim of this study was to evaluate the oncological outcomes of hepatocellular carcinoma patients undergoing liver resection using cavitron ultrasonic surgical aspirator (CUSA) or radiofrequency (RF) based device Habib-4X.

Study Design: We prospectively analyzed the data of 280 patients who underwent liver resection for hepatocellular carcinoma at our institution from 2010-2012 with follow up till August 2016. The CUSA was used in the 163 patients whilst Habib-4X in 117 patients. The end points of analysis were oncological outcomes as disease recurrence, disease-free survival (DFS) and overall survival (OS) were estimated by the Kaplan-Meier method, which has been compared with all other existing literature on the survival study.

Results: Compared with CUSA the reported incidence of recurrence was significantly lower, in Habib-4X group; $p<0.01$. The median DFS was significantly better in Habib-4X group than CUSA group (50.80 vs 45.87 months, $p=0.03$ ). The median OS was better in Habib-4X group than CUSA group (60.57 vs 57.17 months, $p=0.12$ ) though the lesser difference in OS between the groups might be explained by the use of palliative therapies as TACE, percutaneous RFA, etc. in case of recurrence.

Conclusions: RF based device Habib- $4 \mathrm{X}$, is safe and effective device for resection of hepatocellular carcinoma, in comparison to CUSA with better oncological outcomes, i.e., significantly lesser tumour recurrence and better DFS. This could be explained on the basis of systemic and local immunomodulatory effect involving induction of kupffer cells and effector CD-8 T cells that help in minimizing postoperative complications and bring more advantageous oncological outcomes.

\section{INTRODUCTION}

Hepatocellular carcinoma (HCC) has been reported as the fifth most common malignancy and considered as one of the aggressive cancer of mankind. In 2012, the worldwide incidence of $\mathrm{HCC}$ was 782,000 with mortality of 746,000 per year [1]. In the present era, surgical resection of the tumour has been considered as the standard treatment option for early Barcelona classified HCC patients. Moreover, the indication for surgical resection has widened owing to improved knowledge of liver anatomy, anaesthetic techniques, intraoperative ultrasounds and other imaging techniques $[2,3]$. In the last two decades surgical world has witnessed the introduction 
of many devices to ease the technical challenges imposed with liver resection, though the device of choice has remained an issue of debate till date.

The initial prototype technique of liver resection is clamp crush or finger fracture is associated with high incidence of intraoperative bleeding during parenchymal transection and is the major obstacle to surgical success [4]. Excessive blood loss and blood transfusions have further ratified the perioperative morbidity, infections and mortality. Furthermore, it is associated with an increased risk of $\mathrm{HCC}$ recurrence $[5,6]$. To limit the blood flow during parenchymal transection an infamous hepatic vascular inflow occlusion technique or Pringle manoeuvre has been introduced into the practice although its applicability is limited particularly in patients with underlying liver disease owing to an increase risk of ischemic reperfusion injury and inability to control backflow bleed from hepatic veins $[7,8]$.

Early era of liver surgery has evidenced a mortality of $10-20 \%$, which significantly reduced to $5 \%$ with further advancements in the medical science, equipment and operative techniques [9]. Various equipments' of liver resection, such as the CUSA (Cavitron Ultrasonic Surgical Aspirator), RF based Habib-4X, Ligasure (Valley Lab, Tyco Healthcare, Boulder, CO, USA), Harmonic Scalpel (Ethicon Endo-Surgery, Cincinnati, OH, USA), TissueLink (Salient Surgical Technologies, Portsmouth, NH, USA), Water-jet dissection, microwave assisted resection, vascular staplers, and others have been introduced to facilitate easy and safe resection of liver parenchyma. Despite that, the question regarding the clinical benefit of using one over the other still remains unanswered [10].

Cavitron Ultrasonic Surgical Aspirator (CUSA), also known as Ultrasonic Dissector has been first popularized by Hodgson et al. in 1979 [11]. Here, the ultrasonic waves generate energy to fragment and aspirate parenchymal tissue. The contact of oscillating titanium tip causes fragmentation of hepatocytes owing to the high water content while, selectively sparing the blood vessels and bile ducts because of poor tissue water content. As CUSA doesn't coagulate, one needs additional help of ties, clips or staplers as per the surgeon's disposition to achieve haemostasis and biliostasis. Consequently, it results in an explicit line of transection by safeguarding the normal hepatic tissue, though the benefit obtained in terms of reducing the blood loss is not significant [12-14]. The ability of CUSA to selectively modulate tissue dissection depends upon the mechanical resistance offered by the tissue itself, e.g., hepatocytes contain less fibrous tissue than vessels and thus extend less resistance to crushing during parenchymal division. This is a particularly important point for consideration in a cirrhotic liver by virtue of an increased fibrous component [14-16].

Habib's technique, first introduced by Habib in 2002, has received well acceptance as "Bloodless Hepatectomy Technique". The Habib-4X is a bipolar device introduced perpendicularly into the liver in a serial fashion to create a parallel lines of ablation $[17,18]$. This RF based device permits hepatic resection with minimal blood loss [19]. It coagulates all vessels and bile ducts in its field of application thus minimizing the need of Pringle Maneuver and blood transfusion [20].

The present study is the first and largest study done so far to compare the oncological outcomes of CUSA and Habib-4X based liver resection. Based on the prospective analysis of our database, we specifically compared the recurrence rates, DFS and OS following use of these two modalities.

\section{RESULTS}

\section{Demography}

A total of 280 patients with hepatocellular carcinoma who underwent hepatic resection were included in the present study. CUSA based hepatic resection was performed in 163 patients while 117 patients were treated with Habib-4X. Patients' demographic characteristics of each group has been tabulated (Table 1) and compared. The mean age of patients in CUSA and Habib-4X group was $58.39 \pm 11.9$ years and $58.18 \pm 11.37$ years respectively $(p>0.05)$. There were 31 women $(19.0 \%)$ and 132 men $(80.9 \%)$ in the CUSA cohort whilst, 13 women $(26.4 \%)$ and $86(73.5 \%)$ men in the Habib-4X group. Along with that, we didn't observe any significant differences between groups regarding serum albumin, serum bilirubin, serum AFP, tumour numbers, tumour size, tumour stage, cirrhosis, HBsAg, HCV, ICG clearances (Tables 2 and 3).

\section{Procedure and complications}

No significant difference was observed in the number and size of tumours in the CUSA and the Habib$4 \mathrm{X}$ resection groups (Table 2). Major liver resection was done for 45 patients in CUSA group and 27 patients in Habib-4X group with no significant differences $(p=0.43)$. Anatomical resection was accomplished in 63 cases with CUSA while 43 cases were done with Habib-4X ( $p=0.84)$ (Table 3)

The operative blood loss was significantly higher $(271.47 \pm 214.5 \mathrm{~mL})$ in the CUSA group than Habib$4 \mathrm{X}$ group $(150.93 \pm 103.6 \mathrm{~mL} ; p<0.00)$. Furthermore, our results demonstrated single event of vascular inflow control in Habib-4X group compared to 139 in the CUSA group ( $p<0.00$; Table 3$)$.

The length of postoperative hospital stay was comparable for patients in both the groups. The mean length of stay was $7.88 \pm 1.25$ days (5-12 days) in the Habib-4X group compared to $7.84 \pm 2.04$ days (6-21 days) in CUSA group $(p=0.77)$. We reported $0 \%$ mortality as in-patient or within 30 days of hospital admission in both groups (Table 3). 
Table 1: Demographics and clinical characteristics of patients in the study groups

\begin{tabular}{cccc}
\hline Parameters & $\begin{array}{c}\text { CUSA } \\
(\mathbf{1 6 3})\end{array}$ & $\begin{array}{c}\text { Habib-4X } \\
(\mathbf{1 1 7})\end{array}$ & $\boldsymbol{p}$ value \\
\hline Mean age \pm SD (yrs) & $58.39 \pm 11.9$ & $58.14 \pm 11.37$ & 0.85 \\
No. male/female & $132 / 31$ & $86 / 31$ & 0.14 \\
Albumin (g/dl) & $4.28 \pm 0.88$ & $4.05 \pm 1.20$ & 0.08 \\
Bilirubin (mg/dl) & $1.06 \pm 0.86$ & $.97 \pm 0.49$ & 0.27 \\
ICG Clearance (15 mins) & $9.41 \pm 7.2$ & $10.62 \pm 9.4$ & 0.22 \\
AFP (ng/ml) & $1790.02 \pm 7623.98$ & $1901.17 \pm 9763.70$ & 0.91 \\
Cirrhosis & 64 & 51 & 0.47 \\
HBsAg & 112 & 78 & 0.72 \\
HCV & 46 & 40 & 0.29 \\
\hline
\end{tabular}

- Statistical significance was analyzed by the chi-square test.

- Statistical significance was analyzed by the Student's $t$-test

Table 2: Tumour characteristics of patients in study groups

\begin{tabular}{lccc}
\hline Parameters & $\begin{array}{c}\text { CUSA } \\
(\mathbf{1 6 3 )}\end{array}$ & $\begin{array}{c}\text { Habib-4X } \\
(\mathbf{1 1 7})\end{array}$ & $\boldsymbol{p}$ value \\
\hline Tumour Numbers & & & 0.68 \\
1 & 144 & 106 & 0.93 \\
2 & 13 & 9 & 0.58 \\
3 & 4 & 1 & 0.76 \\
4 & 2 & & \\
Tumour Stage & & 79 & 0.76 \\
T1 & 106 & 34 & 0.63 \\
T2 & 53 & 4 & 0.91 \\
T3 & 4 & $4.43 \pm 3.27$ & 0.56 \\
Tumour Size (cm) & $4.66 \pm 3.43$ & & \\
\hline
\end{tabular}

- Statistical significance was analyzed by the chi-square test.

- Statistical significance was analyzed by the Student's $t$-test.

The major complications as post hepatectomy liver failure, bile leakage, bleeding were higher in CUSA group than Habib-4X although not reached any statistical significance ( $p=0.36$; Table 3 ).

The data analysis of tumour histology showed that free resection margins were comparable in both groups i.e., 91 cases with CUSA than 57 cases in Habib-4X group $(p=0.29)$ also vascular invasion were comparable (Table 5).

\section{Recurrence}

We registered significantly lower recurrence in the Habib-4X group (44 patients) as compared to the patients treated with CUSA (85 patients; $p<0.01$ ) (Table 4). Similarly, the percent of patients who received other palliative interventions post recurrences were significantly higher for the CUSA group i.e., $81.1 \%$ compared to $62.4 \%$ in Habib-4X group $(p<0.01)$ The further analysis of the data showed RF ablation as the most common modality of palliation in CUSA group $(47 / 85 ; 55.3 \%)$ compared to Habib-4X (8/44; 18.1\%); The TACE was the second most common modality of palliation required in $23 / 85 ; 27 \%$ cases of CUSA group compared to $21 / 44 ; 47.7 \%$ cases in Habib-4X group (Table 4).

\section{Survival}

The median duration of disease-free survival was significantly longer in the Habib-4X group (50.80 months) than CUSA group (45.87 months; $p=0.03$ ). Five-year disease free survival was $56 \%$ in the Habib$4 \mathrm{X}$ group compared to $54 \%$ in the CUSA group while the corresponding overall survival rates for the Habib$4 \mathrm{X}$ group and CUSA group were $61 \%$ and $51.30 \%$ respectively (Table 5; Figure 1). Although, the median 
Table 3: Operative and postoperative characteristics of patients in study groups

\begin{tabular}{lccc}
\hline Parameters & $\begin{array}{c}\text { CUSA } \\
(\mathbf{1 6 3 )}\end{array}$ & $\begin{array}{c}\text { Habib-4X } \\
(\mathbf{1 1 7})\end{array}$ & $\boldsymbol{p}$-value \\
\hline Anatomical resection & 63 & 43 & 0.84 \\
Non-anatomical resection & 100 & 74 & 0.84 \\
Major resection & 45 & 27 & 0.43 \\
Minor resection & 116 & 90 & 0.43 \\
Blood Loss (mL) & $271.47 \pm 214.5$ & $150.93 \pm 103.6$ & $0.00^{*}$ \\
(Mean \pm SD) & 21 & 3 & $0.00^{\#}$ \\
Blood transfusion received & 139 & 1 & $0.00^{\#}$ \\
Vascular Inflow Control & $7.84 \pm 2.04$ & $7.88 \pm 1.25$ & 0.77 \\
Hospital Stay (Days) & 4 & 0 & \\
(Mean \pm SD) & 4 & 1 & \\
Post hepatectomy liver failure & 0 & 2 & \\
Bile leakage & 1 & 0 & 0.36 \\
Sepsis & 9 & 3 & \\
Bleeding & & & \\
Major complication & & & \\
\hline
\end{tabular}

- *\#\$ Showing Significant $p$-value.

- "Statistical significance was analyzed by the chi-square test.

- "Statistical significance was analyzed by the Student's $t$-test.

- 'Statistical significance was analyzed by the Mann-Whitney $U$ test.

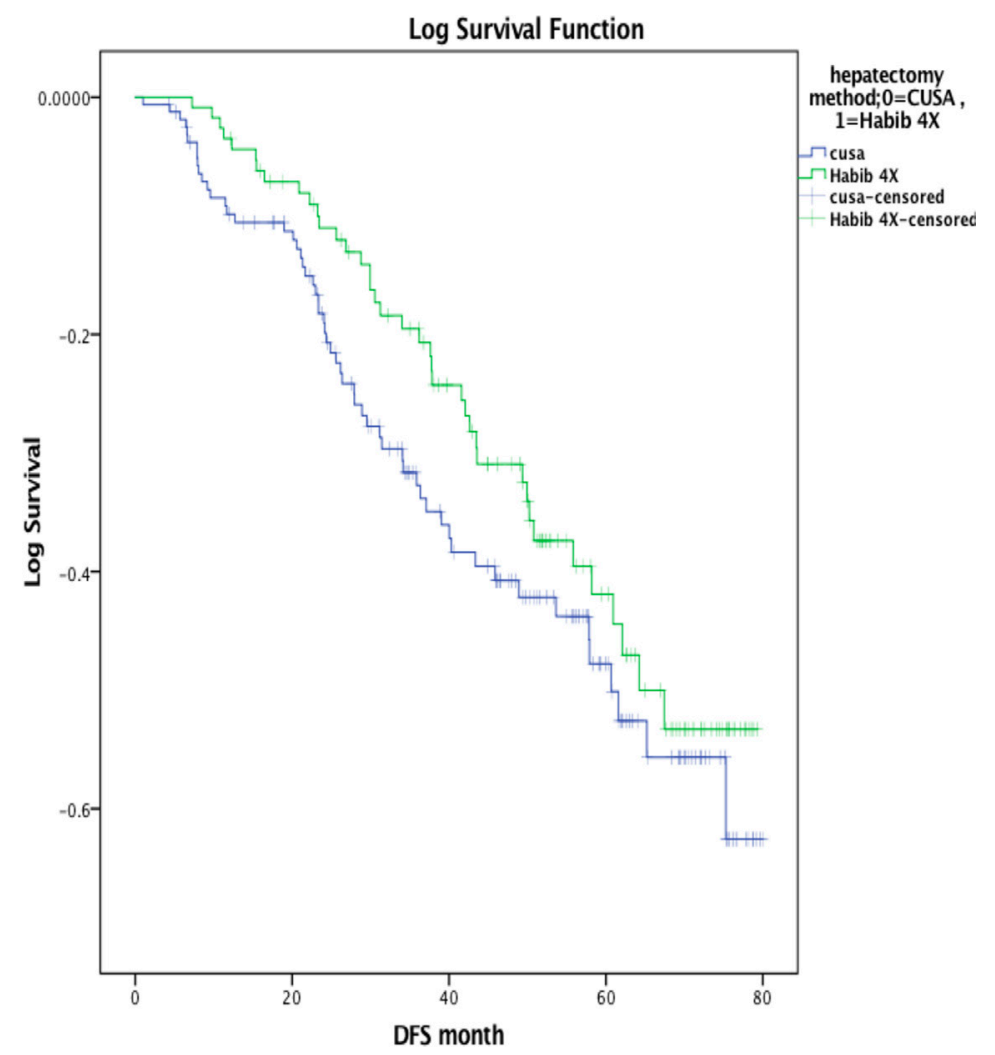

Figure 1: Disease-free survival (DFS) estimates. Kaplan-Meier survival plot of DFS comparing CUSA group (Blue line) with the Habib-4X group (Green line) $(p=0.03)$. 
Table 4: Comparison with number of interventions post-recurrence within studied groups

\begin{tabular}{lccc}
\hline Parameters & $\begin{array}{c}\text { CUSA } \\
(\mathbf{1 6 3 )}\end{array}$ & $\begin{array}{c}\text { Habib-4X } \\
(\mathbf{1 1 7})\end{array}$ & $\boldsymbol{p}$ value \\
\hline Recurrence $(-/+)$ & $78 / \mathbf{8 5}$ & $73 / \mathbf{4 4}$ & $0.01^{\#}$ \\
Intervention done in cases of recurrence $(-/+)(\%)$ & $78 / \mathbf{8 5}$ & $73 / \mathbf{4 4}$ & $0.00^{\#^{* *}}$ \\
& $\mathbf{( 8 1 . 1 \% )}$ & $\mathbf{( 6 2 . 4 \% )}$ & \\
RFA & 47 & 8 & \\
TACE & 23 & 21 & \\
Re-operation & 9 & 3 & \\
Sorafenib & 5 & 12 & \\
Radiotherapy & 1 & 0 & \\
\hline
\end{tabular}

- \#* Showing Significant $p$-value.

- ${ }^{*}$ Degree of freedom $=5$.

- \#Statistical significance was analyzed by the chi-square test.

Table 5: Postoperative tumour characteristics of patients in study groups

\begin{tabular}{lccc}
\hline Parameters & $\begin{array}{c}\text { CUSA } \\
\mathbf{( 1 6 3 )}\end{array}$ & $\begin{array}{c}\text { Habib-4X } \\
(\mathbf{1 1 7})\end{array}$ & $\boldsymbol{p}$-value \\
\hline Resection margin & & & \\
$\quad$ Free & 91 & 57 & 0.29 \\
$\quad$ Free within $1 \mathrm{~cm}$ & 63 & 52 & 0.39 \\
$\quad$ Involved & 9 & 6 & 0.82 \\
Vascular invasion & 42 & 27 & 0.67 \\
Local Recurrence & 5 & 3 & $0.80^{\#}$ \\
Recurrence (-/+) & $78 / 85$ & $73 / 44$ & $0.01^{\#}$ \\
Disease Free Survival (Median) (months) & 45.87 & 50.80 & $0.03^{\mathrm{s}}$ \\
Overall Survival (Median) (months) & 57.17 & 60.57 & 0.11 \\
\hline
\end{tabular}

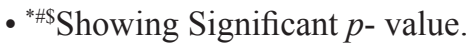

- "Statistical significance was analyzed by the chi-square test.

- "Statistical significance was analyzed by the Student's $t$-test.

- Statistical significance was analyzed by the Mann-Whitney $U$ test.

overall survival was better in Habib-4X group than CUSA group but was not statistically significant (60.57 vs 57.17 months, $p=0.12$ ) (Table 5).

\section{DISCUSSION}

Studies have proved that surgical resection confers better likelihood of cure and survival in patients suffering from early stage of HCC [21, 22]. Nevertheless, disagreement exists regarding the most efficacious and safest modality of liver resection. Current evidence indicates that the stage of parenchymal transection during surgery has maximum impact on blood loss, blood transfusion, post-operative complications and bile leak. Furthermore, this has also influenced the oncological outcomes such as survival and tumour recurrence [23-26]. Studies have shown that Habib-4X provides favourable operative outcomes in terms of blood loss, post-operative recovery, hospital stay, postoperative morbidity and mortality $[17,27,28]$. Till date, many studies have looked into the safety and efficacy of various modalities for hepatic parenchymal resection, however very few studies have compared the long-term outcomes of these techniques [29]. The disease recurrence and survival are considered as the most important factors determining the therapeutic success in management of malignant disease. To the best of our knowledge, this is the first study to investigate into the oncological outcomes following the use of CUSA or Habib-4X for liver resection. Here we matched and compared both groups to minimize confounders as serum albumin, serum bilirubin, serum AFP, tumour numbers, tumour size, tumour stage, cirrhosis, HBsAg, HCV, ICG clearances, type of resection (major/minor and anatomical/ non-anatomical), resection margin, tumour number, size and stage, and vascular invasion. The data analysis showed 
that both groups were comparable against above outlined parameters with no significant difference $(p<0.05)$ and has increased significant strength to our study.

The analysis of immediate outcomes in our study showed that the mean blood loss, need for blood transfusion, and requirement for vascular inflow control was significantly lower in the Habib-4X group than the CUSA group. This might be explained by the fact that Habib-4X utilizes radiofrequency energy to coagulate the blood vessels while the ability of CUSA has been limited by the need of manual activation to coagulate the blood vessels [30-33]. In accordance with a previous study, we also found that surgeon's experience in using CUSA has an influence on the surgical outcome [34].

The length of hospital stay did not reach statistical significance in either study group, however this appeared similar to other existing reports. The present study didn't report any mortality in either group which could be attributed to the recent advances in the surgical techniques and better peri-operative and post-operative management making hepatic resection a reasonably safe treatment option.

As, recurrence following curative surgery in patients with HCC remains a major clinical hurdle while deciding the best treatment strategy. We demonstrated significantly lower recurrence with the RF based device Habib-4X. One of the reasons accounting for the present oncological outcomes are based on the coagulating property of RF ablation which minimises blood loss and the need for blood transfusion; prevents any tumour spillage and micro metastasis. The lower recurrence could also be attributed to the favourable systemic and local immunomodulatory changes induced by the RF resection [34-36].

The further data analysis of long term outcomes has demonstrated significantly better disease-free survival for the patients who underwent RF based liver resection for HCC. The disease-free survival rates were $95 \%$ at 1 year, $96 \%$ at 2 years, $88 \%$ at 3 years, $67 \%$ at 4 years and $56 \%$ at 5 years, (Table 6 ) which was not only better than the CUSA group but also stands in accordance with the previous notable studies [23, 37-53]. We also evidenced better overall survival in the Habib-4X group, although, it did not reach statistical significance. This might be because the recurrence of cancer did affect the disease free survival though this was not reflected in terms of overall survival. The inability to reach statistical significance could be explained by the higher use of palliative treatment modalities like percutaneous RF ablation, TACE, sorafenib etc. in the CUSA group in instances of recurrence which helps in prolonging life despite recurrence of the disease. This has facilitated the importance of Habib-4X in providing better disease free survival and this further supports the recently published study Qiu et al. where they reported significantly better recurrence free survival and overall survival with Habib4X compared to the clamp-crush technique [54].
Following initial hepatic resection, $81.1 \%$ patients in CUSA group while $62.4 \%$ in Habib-4X required retreatment. Further analysis of data showed that RF ablation was the most common modality of palliation (55.3\%) in the CUSA recurrence group while it constituted only $18.1 \%$ of palliation in the Habib- $4 \mathrm{X}$ group. The findings further strengthened the role of Habib-4X as a better modality of treatment over CUSA in HCC management.

The favourable oncological outcomes with Habib4X could be explained by the virtue of systemic and local immunomodulatory effect of radiofrequency. The debris produced following RF-induced coagulative necrosis during HCC resection releases tumour antigens and chemokines. These chemokines attract inflammatory infiltrates; neutrophils, macrophages, NK cells, dendritic cells (DCs), as well as CD4+ and CD8+ T lymphocytes. The cellular influx at the ablated resection margin phagocytoses the debris and tumour cells. Tumour antigens also drain to nearby lymph nodes, and stimulate immature DCs and naive T-cells thus provide systemic immunomodulation [55-58].

The liver is a unique organ which maintains intricate balance between not over-reacting to the antigens absorbed by the gut and mounting accurate immune responses to eliminate the tumor antigen. HCC is characterized by chronic inflammation and immune suppression. Immunosuppression due to inhibitory checkpoints appear to be an important contributor to the induced immune suppression in this setting and subsequent development and progression of HCC. Tregs and myeloid-derived suppressor cells are thought to play an important role in protecting the tumour from eradication by activated cytotoxic CD8+ T cells. High level of Tregs in tumor has been linked to poor prognosis in HCC [59-62].

Over the last two years, major breakthrough in immunological understanding in the tumour management has led to the development of newer drugs as checkpoint inhibitors which boost $\mathrm{CD} 8+\mathrm{T}$ cell functioning. The discovery of these drugs have brought significant improvement in the survival of patients with cancers like leukaemia, lymphoma and melanoma, although the same has not been translated for HCC. One of the great potentials of RF based therapies are that they can dovetail with immune modulating therapies. RF ablation induces $\mathrm{CD} 8+\mathrm{T}$ cells infiltration at the ablation site and further addition of a checkpoint inhibitor might act as a booster. The potential effect on the immune system is further advantageous in terms of better survival as it acts in synergy with checkpoint inhibitors. In addition, recent trials have shown that combined use of RF and checkpoint inhibitors could bring more beneficence towards the longterm survival [63-66]. This has been further strengthened by the study of Duffy et al., 2017, where they reported the activation of the immune system through checkpoint inhibitors and accumulation of intratumoral CD8+ T cells 
Table 6: Detailed comparison of disease free survival for the study groups

\begin{tabular}{lcc}
\hline $\begin{array}{l}\text { Parameters } \\
\text { (Time in Months) }\end{array}$ & $\begin{array}{c}\text { CUSA } \\
\text { (163) }\end{array}$ & $\begin{array}{c}\text { Habib-4X } \\
\text { (117) }\end{array}$ \\
\hline 12 months & $93 \%$ & $95 \%$ \\
24 months & $87 \%$ & $96 \%$ \\
36 months & $86 \%$ & $88 \%$ \\
48 months & $66 \%$ & $67 \%$ \\
60 months & $54 \%$ & $56 \%$ \\
\hline
\end{tabular}

following RF ablation, thus demonstrating the synergism of combined use of checkpoint inhibitor tremelimumab and ablation in aggressive hepatocellular carcinomas [67].

The present study has certain limitations owing to its retrospective design and unintended biases of patient selection which might influence the analysis. In spite of these limitations, this study has outlined significantly better disease free survival and lesser tumour recurrence with the Habib-4X group compared to the CUSA group.

\section{MATERIALS AND METHODS}

\section{Study design}

In this multicentric study, the data from two centers of National Taiwan University Hospital were prospectively collected and analyzed after obtaining approval from the Institutional Review Board. The data included 280 patients with confirmed diagnosis of $\mathrm{HCC}$ on histopathology who underwent liver resection with CUSA or RFA based device Habib-4X from January 2010 till December 2012 and were followed-up till August 2016. The data was collected for the amount of blood loss, vascular inflow control, length of hospitalization, complication within 30 days, post hepatectomy liver failure (PHLF) overall recurrences, local recurrences and interventions done in cases of recurrences. PHLF was measured according to the definition set by International Study Group of Liver Surgery (ISGLS) 2011 [68]. The endpoints of the study as overall survival and disease free survival were estimated by the Kaplan-Meier method.

\section{Procedure}

All patients with a diagnosis of $\mathrm{HCC}$ underwent open surgical hepatectomy under guidance of intra-operative ultrasound. Both the lobes of liver were mobilized and gall bladder was removed if needed. Selective inflow control was performed in cases of excessive parenchymal bleeding. In cases where CUSA had been used by the surgeon, help of an assistant surgeon was needed to control the bleeding with bipolar coagulation, while no assisting haemostatic instrument was required during resection in the Habib-4X group. The Habib-4X, a bipolar device was introduced perpendicularly into the liver in a serial fashion to create parallel lines of ablation. The third line of ablation was created perpendicular to the parallel track, following which liver was resected by scalpel. The probe was moved swiftly in see-saw fashion for 3-5 $\mathrm{mm}$ in its axis of application. The movement of probe helped in averting any adherence of the liver tissue. The device effectively created a $1 \mathrm{~cm}$ thick area of ablated and coagulated tumour free margin $[16,17]$. A meticulous hemostasis was assured, and raw surface covered by cellulose hemostatic agent. In the present study, a major hepatectomy was defined as resection of three or more liver segments.

\section{Statistical analysis}

Overall survival and disease-free survival were calculated from the date of surgical intervention. Continuous variables were analyzed with Student's $t$-test, and categorical variables were analyzed with chi-square or Fisher's Exact Test where appropriate. Survival and recurrence rates were calculated using the Kaplan- Meier method and comparison between groups were done with the log-rank test. Predictors of overall and disease-free survival were analyzed by performing a Cox Proportional Hazards regression model using a backwards selection process. A $p$-value of $<0.05$ was considered significant in this study. Data were fed into a Microsoft Excel worksheet and analyzed by the IBM-SPSS version 24 (SPSS Inc, Chicago, IL, USA).

\section{Literature review}

A comprehensive systematic literature review was performed to search all the published articles on National Library of Medicine Database (PUBMED), EMBASE, Cochrane, CrossRef, and Scopus databases on 15th November 2016 describing the outcomes of hepatic resection in hepatocellular carcinoma. The search covered the period from January 1st, 1981 to November 15th, 2016. The search was carried out by using the medical subject headings (MeSH) terms: 'Hepatocellular Carcinoma', 'Liver Neoplasm', 'Hepatectomy open', 'Hepatectomy laparoscopic'. The initial search yielded a total of 154 manuscripts. Following the careful evaluation of inclusion, exclusion criterias and demography characteristics, 137 
Table 7: Literature review of survival outcomes of hepatic resection in hepatocellular carcinoma

\begin{tabular}{lccccccc}
\hline Author & Year & $\begin{array}{c}\text { Study } \\
\text { Sample }\end{array}$ & $\begin{array}{c}\text { Hospital } \\
\text { Mortality } \\
\text { (\%) }\end{array}$ & $\begin{array}{c}\text { Median Survival } \\
\text { (month) }\end{array}$ & \multicolumn{2}{c}{ Overall Survival (\%) } \\
\cline { 7 - 8 } Heng-Jun et al. [37] & 2014 & 151 & - & 61.8 & 99 & 68 & 52 \\
Jin et al. [40] & 2014 & 62 & 11.1 & - & 83.2 & 75.7 & 65 \\
Jianyong et al. [38] & 2014 & 433 & 2.3 & - & 91.8 & 84.2 & 70.8 \\
Nojiri et al. [41] & 2014 & 107 & - & - & - & 62 & 38.1 \\
Lim et al. [42] & 2014 & 172 & 1 & - & - & - & 58 \\
Yin et al. [43] & 2014 & 88 & 11.3 & 41 & 76.1 & 51.5 & - \\
Zhong et al. [21] & 2014 & 660 & 2.6 & - & 91 & 67 & 44 \\
Zhong et al. [44] & 2013 & 257 & 3.1 & $42.9 \pm 26.1$ & 84 & 59 & 37 \\
Cheng et al. [45] & 2012 & 104 & 7.3 & - & 90 & - & 66 \\
Hsu et al. [46] & 2012 & 268 & 2.7 & - & 81 & 63 & 43 \\
Lin et al. [52] & 2010 & 93 & 5.4 & $29.9 \pm 20.1$ & 83 & 49 & - \\
Ho et al. [47] & 2009 & 294 & - & 37.9 & 77.4 & 51.9 & 36.6 \\
Wang et al. [48] & 2008 & 243 & - & $60.4 \pm 6.1$ & 81.5 & 64.4 & 50.5 \\
Lee et al. [49] & 2007 & 100 & 2 & - & 66 & 44 & 31 \\
Pandey et al. [53] & 2007 & 166 & 3 & - & - & - & 29 \\
Ng et al. [50] & 2005 & 380 & 2.7 & - & 74 & 50 & 39 \\
Poon et al. [51] & 2002 & 120 & 5 & - & 61 & 38 & 28 \\
Present Study & 2016 & 117 & 1.5 & 60.6 & 95 & 86 & 56 \\
\hline
\end{tabular}

articles were excluded. The remaining 17 papers, were considered, and full-text obtained (Table 7).

\section{CONCLUSIONS}

The present study reported better oncological outcomes including significantly lesser tumour recurrence and better disease free survival following Habib-4X based tumour resection for hepatocellular cancer as compared to CUSA.

The small difference in terms of OS between the two groups could be explained by the use of palliative therapeutic modalities in the patients with tumour recurrence. Habib-4X is a feasible, promising and safe liver resection device with excellent short and long term results and with a potential to be used with checkpoint inhibitors. Nevertheless, these findings need to be confirmed with more prospective and randomized controlled trials.

\section{CONFLICTS OF INTEREST}

Prof. Nagy Habib is a shareholder and Director of the company, EMcision Limited, that originally developed the Habib ${ }^{\text {TM }}$ 4X. Since 2005 the Habib ${ }^{\text {TM }} 4 \mathrm{x}$ has not been marketed or sold by EMcision Limited. All the other authors have no conflicts of interest, including specific financial interests or relationships and affiliations relevant to the subject matter or materials discussed in the manuscript.

\section{REFERENCES}

1. McGlynn KA, Petrick JL, London WT. Global Epidemiology of Hepatocellular Carcinoma: An Emphasis on Demographic and Regional Variability. Vol. 19, Clinics in Liver Disease. 2015. p. 223-38.

2. Tohme S, Geller DA, Cardinal JS, Chen HW, Packiam V, Reddy S, Steel J, Marsh JW, Tsung A. Radiofrequency ablation compared to resection in early-stage hepatocellular carcinoma. HPB. 2013; 15:210-7.

3. Duan C, Liu M, Zhang Z, Ma K, Bie P. Radiofrequency ablation versus hepatic resection for the treatment of earlystage hepatocellular carcinoma meeting Milan criteria: a systematic review and meta-analysis. World J Surg Oncol. 2013; 11:190.

4. Lin TY. A simplified technique for hepatic resection: the crush method. Ann Surg. 1974; 180:285-90.

5. Kooby DA, Stockman J, Ben-Porat L, Gonen M, Jarnagin WR, Dematteo RP, Tuorto S, Wuest D, Blumgart LH, Fong Y. Influence of transfusions on perioperative and long-term outcome in patients following hepatic resection for colorectal metastases. Ann Surg. 2003; 237:860-70.

6. Yamamoto J, Kosuge T, Takayama T, Shimada K, Yamasaki S, Ozaki H, Yamaguchi N, Mizuno S, Makuuchi M. Perioperative blood transfusion promotes recurrence of hepatocellular carcinoma after hepatectomy. Surgery. 1994; 115:303-9. 
7. Kim YI. Ischemia-reperfusion injury of the human liver during hepatic resection. J Hepatobiliary PancreatSurg. 2003; 10:195-9.

8. Sugiyama Y, Ishizaki Y, Imamura H, Sugo H, Yoshimoto J, Kawasaki S. Effects of intermittent Pringle's manoeuvre on cirrhotic compared with normal liver. Br J Surg. 2010; 97:1062-9.

9. Jarnagin WR, Gonen M, Fong Y, DeMatteo RP, Ben-Porat L, Little S, Corvera C, Weber S, Blumgart LH. Improvement in perioperative outcome after hepatic resection: analysis of 1,803 consecutive cases over the past decade. Ann Surg. 2002; 236:397-406; discussion 406-7.

10. Poon RTP. Current techniques of liver transection. HPB (Oxford). 2007; 9:166-73.

11. Williams JW, Hodgson WJ. Histologic evaluation of tissues sectioned by ultrasonically powered instruments (a preliminary report). Mt Sinai J Med. 1979; 46:105-6.

12. Takayama T, Makuuchi M, Kubota K, Harihara Y, Hui AM, Sano K, Ijichi M, Hasegawa K. Randomized comparison of ultrasonic vs clamp transection of the liver. Arch Surg. 2001; 136:922-8.

13. Lesurtel M, Selzner M, Petrowsky H, McCormack L, Clavien PA. How should transection of the liver be performed?: a prospective randomized study in 100 consecutive patients: comparing four different transection strategies. Ann Surg. 2005; 242:814-22, NaN-3.

14. Bodzin AS, Leiby BE, Ramirez CG, Frank AM, Doria C. Liver resection using cavitron ultrasonic surgical aspirator (CUSA) versus harmonic scalpel: A retrospective cohort study. Int J Surg. 2014; 12:500-3.

15. Fasulo F, Giori A, Fissi S, Bozzetti F, Doci R, Gennari L. Cavitron Ultrasonic Surgical Aspirator (CUSA) in liver resection. Int Surg. 1992; 77:64-6.

16. Choi JS. Cavitron Ultrasonic Surgical Aspirator. SAGES Man Fundam Use Surg Energy. 2012;133-8.

17. Pai M, Jiao LR, Khorsandi S, Canelo R, Spalding DRC, Habib N. Liver resection with bipolar radiofrequency device: Habib 4X. HPB (Oxford). 2008; 10:256-60.

18. Hiroishi K, Eguchi J, Baba T, Shimazaki T, Ishii S, Hiraide A, Sakaki M, Doi H, Uozumi S, Omori R, Matsumura T, Yanagawa T, Ito T, Imawari M. Strong CD8(+) T-cell responses against tumor-associated antigens prolong the recurrence-free interval after tumor treatment in patients with hepatocellular carcinoma. J Gastroenterol. 2010; 45:451-8.

19. Navarra G, Spalding D, Zacharoulis D, Nicholls JP, Kirby S, Costa I, Habib NA. Bloodless hepatectomy technique. HPB (Oxford). 2002; 4:95-7.

20. Weber JC, Navarra G, Jiao LR, Nicholls JP, Jensen SL, Habib NA. New technique for liver resection using heat coagulative necrosis. Ann Surg. 2002; 236:560-3.

21. Zhong JH, Ke Y, Gong WF, Xiang B, Ma L, Ye XP, Peng T, Xie GS, Li LQ. Hepatic resection associated with good survival for selected patients with intermediate and advanced-stage hepatocellular carcinoma. Ann Surg. 2014; 260:329-40.
22. Liu W, Wang K, Bao Q, Sun Y, Xing BC. Hepatic resection provided long-term survival for patients with intermediate and advanced-stage resectable hepatocellular carcinoma. World J Surg Oncol. 2016; 14:62.

23. Abdalla EK, Vauthey JN, Ellis LM, Ellis V, Pollock R, Broglio KR, Hess K, Curley SA. Recurrence and outcomes following hepatic resection, radiofrequency ablation, and combined resection/ablation for colorectal liver metastases. Ann Surg. 2004; 239:818-25; discussion 825-7.

24. Kooby DA, Stockman J, Ben-Porat L, Gonen M, Jarnagin WR, Dematteo RP, Tuorto S, Wuest D, Blumgart LH, Fong Y. Influence of transfusions on perioperative and long-term outcome in patients following hepatic resection for colorectal metastases. Ann Surg. 2003; 237:860-9; discussion 869-70.

25. Stephenson KR, Steinberg SM, Hughes KS, Vetto JT, Sugarbaker PH, Chang AE. Perioperative blood transfusions are associated with decreased time to recurrence and decreased survival after resection of colorectal liver metastases. Ann Surg. 1988; 208:679-87.

26. Finch RJB, Malik HZ, Hamady ZZR, Al-Mukhtar A, Adair R, Prasad KR, Lodge JPA, Toogood GJ. Effect of type of resection on outcome of hepatic resection for colorectal metastases. Br J Surg. 2007; 94:1242-8.

27. El-Gendi AM, Khorsandi SE, Pai M, Zacharoulis D, Nicholls JP, Spalding DR, Jiao LR, Habib NA. Repeat hepatic resection using a radiofrequency-assisted technique. Dig Surg. 2008; 25:293-9.

28. Chen J, Dong X, Tang Z, Gao S, Wu Y, Fang H. Zhonghua Yi Xue Za Zhi. Clinical study of liver resection with bipolar radiofrequency device: Habib 4X. 2013; 93:2553-6.

29. Pamecha V, Gurusamy KS, Sharma D, Davidson BR. Techniques for liver parenchymal transection: A metaanalysis of randomized controlled trials. Vol. 11, HPB. 2009. p. 275-81.

30. Doklestić K, Karamarković A, Stefanović B, Stefanović B, Milić N, Gregorić P, Djukic V, Bajec D. The efficacy of three transection techniques of liver resection: A randomized clinical trial. Hepatogastroenterology. 2012; 59:1501-6.

31. Lesurtel M, Belghiti J. Open hepatic parenchymal transection using ultrasonic dissection and bipolar coagulation. HPB (Oxford). 2008; 10:265-70.

32. Rahbari NN, Elbers H, Koch M, Vogler P, Striebel F, Bruckner T, Mehrabi A, Schemmer P, Buchler MW, Weitz J. Randomized clinical trial of stapler versus clamp-crushing transection in elective liver resection. Br J Surg. 2014; 101:200-7.

33. Aldrighetti L, Pulitanò C, Arru M, Catena M, Guzzetti E, Casati M, Ferla G. Ultrasonic-mediated laparoscopic liver transection. Am J Surg. 2008; 195:270-2.

34. Haen SP, Pereira PL, Salih HR, Rammensee HG, Gouttefangeas C. More than just tumor destruction: Immunomodulation by thermal ablation of cancer. Vol. 2011, Clinical and Developmental Immunology. 2011.

35. Zerbini A, Pilli M, Penna A, Pelosi G, Schianchi C, Molinari A, Schivazappa S, Zibera C, Fagnoni FF, Ferrari C, Missale 
G. Radiofrequency thermal ablation of hepatocellular carcinoma liver nodules can activate and enhance tumorspecific T-cell responses. Cancer Res. 2006; 66:1139-46.

36. Mizukoshi E, Nakamoto Y, Arai K, Yamashita T, Sakai A, Sakai Y, Kagaya T, Yamashita T, Honda M, Kaneko S. Comparative analysis of various tumor-associated antigenspecific t-cell responses in patients with hepatocellular carcinoma. Hepatology. 2011; 53:1206-16.

37. Heng-Jun G, Yao-Jun Z, Min-Shan C. Rationality and effectiveness of transarterial chemoembolization as an initial treatment for BCLC B stage HBV-related hepatocellular carcinoma. Liver Int. 2014;34.

38. Jianyong L, Lunan Y, Wentao W. Barcelona clinic liver cancer stage B hepatocellular carcinoma: transarterial chemoembolization or hepatic resection?. Med. 2014;93.

39. Cheng CH, Yu MC, Wu TH. Surgical resection of centrally located large hepatocellular carcinoma. Chang Gung Med J. 2012;35.

40. Jin YJ, Lee JW, Choi YJ. Surgery versus transarterial chemoembolization for solitary large hepatocellular carcinoma of BCLC stage A. J Gastrointest Surg. 2014;18.

41. Nojiri K, Tanaka K, Takeda K, Ueda M, Matsuyama R, Taniguchi K, Kumamoto T. The efficacy of liver resection for multinodular hepatocellular carcinoma. Anticancer Res. 2014; 34:2421-6.

42. Lim C, Mise Y, Sakamoto Y. Above $5 \mathrm{~cm}$, size does not matter anymore in patients with hepatocellular carcinoma. World J Surg. 2014;38.

43. Yin L, Li H, Li AJ. Partial hepatectomy vs. transcatheter arterial chemoembolization for resectable multiple hepatocellular carcinoma beyond Milan Criteria: a RCT. J Hepatol. 2014;61.

44. Zhong JH, Xiang BD, Gong WF. Comparison of long-term survival of patients with BCLC stage B hepatocellular carcinoma after liver resection or transarterial chemoembolization. PLoS One. 2013;8. Available from: http:/ dx.doi.org/10.1371/journal.pone.0068193

45. Cheng $\mathrm{CH}, \mathrm{Yu} \mathrm{MC}, \mathrm{Wu} \mathrm{TH}$, Lee CF, Chan KM, Chou HS, Lee WC. Surgical resection of centrally located large hepatocellular carcinoma. Chang Gung Med J. 2012; 35:178-91.

46. Hsu CY, Hsia CY, Huang YH, Su CW, Lin HC, Pai JT, Loong CC, Chiou YY, Lee RC, Huo TI, Lee SD. Comparison of Surgical Resection and Transarterial Chemoembolization for Hepatocellular Carcinoma beyond the Milan Criteria: A Propensity Score Analysis. Ann Surg Oncol. 2011.

47. Ho MC, Huang GT, Tsang YM. Liver resection improves the survival of patients with multiple hepatocellular carcinomas. Ann Surg Oncol. 2009;16.

48. Wang JH, Changchien CS, Hu TH, Lee CM, Kee KM, Lin CY, Chen CL, Chen TY, Huang YJ, Lu SN. The efficacy of treatment schedules according to Barcelona Clinic Liver Cancer staging for hepatocellular carcinoma - Survival analysis of 3892 patients. Eur J Cancer. 2008; 44:1000-6.
49. Lee SG, Hwang S, Jung JP. Outcome of patients with huge hepatocellular carcinoma after primary resection and treatment of recurrent lesions. Br J Surg. 2007;94.

50. Ng KK, Vauthey JN, Pawlik TM. Is hepatic resection for large or multinodular hepatocellular carcinoma justified? Results from a multi-institutional database. Ann Surg Oncol. 2005; 12 .

51. Poon RT, Fan ST, Wong J. Selection criteria for hepatic resection in patients with large hepatocellular carcinoma larger than $10 \mathrm{~cm}$ in diameter. J Am Coll Surg. 2002;194.

52. Lin CT, Hsu KF, Chen TW. Comparing hepatic resection and transarterial chemoembolization for Barcelona Clinic Liver Cancer (BCLC) stage B hepatocellular carcinoma: change for treatment of choice?. World J Surg. 2010;34.

53. Pandey D, Lee KH, Wai CT, Wagholikar G, Tan KC. Long term outcome and prognostic factors for large hepatocellular carcinoma (10 cm or more) after surgical resection. Ann Surg Oncol. 2007; 14:2817-23.

54. Qiu J, Lu W, Yu N, Yang G, Li Y, Huang Z, Li J, Li K, Xu H, Chen S, Zeng X, Liu H. HabibTM 4X-assisted resection versus clamp-crush resection for hepatocellular carcinoma: a propensity-matching study. Oncotarget. United States; 2017; 8:4218-27. http://doi.org/10.18632/oncotarget.13906.

55. Waitz R, Solomon SB. Can local radiofrequency ablation of tumors generate systemic immunity against metastatic disease? Radiology. 2009; 251:1-2.

56. Gameiro SR, Higgins JP, Dreher MR, Woods DL, Reddy G, Wood BJ, Guha C, Hodge JW. Combination Therapy with Local Radiofrequency Ablation and Systemic Vaccine Enhances Antitumor Immunity and Mediates Local and Distal Tumor Regression. PLoS One. 2013;8.

57. Rozenblum N, Zeira E, Bulvik B, Gourevitch S, Yotvat H, Galun E, Goldberg SN. Radiofrequency Ablation: Inflammatory Changes in the Periablative Zone Can Induce Global Organ Effects, including Liver Regeneration. Radiology. 2015; 276:416-25.

58. Kim YS, Rhim H, Lim HK, Choi D, Lee MW, Park MJ. Coagulation necrosis induced by radiofrequency ablation in the liver: histopathologic and radiologic review of usual to extremely rare changes. Radiographics. 2011; 31:377-90.

59. Grivennikov SI, Greten FR, Karin M. Immunity, Inflammation, and Cancer. Vol. 140, Cell. 2010. p. 883-99.

60. Chen DS, Mellman I. Oncology meets immunology: The cancer-immunity cycle. Vol. 39, Immunity. 2013. p. 1-10.

61. Aravalli RN. Role of innate immunity in the development of hepatocellular carcinoma. World J Gastroenterol. 2013; 19:7500-14.

62. Farazi PA, DePinho RA. Hepatocellular carcinoma pathogenesis: from genes to environment. Nat Rev Cancer. 2006; 6:674-87.

63. Xu Q, Kobayashi S, Ye X, Meng X. Comparison of Hepatic Resection and Radiofrequency Ablation for Small Hepatocellular Carcinoma: A Meta-Analysis of 16,103 Patients. Sci Rep. 2014; 4:7252. 
64. Shi L, Chen L, Wu C, Zhu Y, Xu B, Zheng X, Sun M, Wen W, Dai X, Yang M, Lv Q, Lu B, Jiang J. PD-1 blockade boosts radiofrequency ablation-elicited adaptive immune responses against tumor. Clin Cancer Res. 2016; 22:1173-84.

65. Tumeh PC, Harview CL, Yearley JH, Shintaku IP, Taylor EJM, Robert L, Chmielowski B, Spasic M, Henry G, Ciobanu V, West AN, Carmona M, Kivork C, et al. PD-1 blockade induces responses by inhibiting adaptive immune resistance. Nature. 2014; 515:568-71.

66. Ito $\mathrm{F}, \mathrm{Ku} \mathrm{AW}$, Bucsek MJ, Muhitch JB, Vardam-Kaur T, Kim M, Fisher DT, Camoriano M, Khoury T, Skitzki JJ, Gollnick SO, Evan SS. Immune Adjuvant Activity of PreResectional Radiofrequency Ablation Protects against Local and Systemic Recurrence in Aggressive Murine Colorectal Cancer. PLoS One. 2015; 10:e143370.
67. Duffy AG, Ulahannan SV, Makorova-Rusher O, Rahma O, Wedemeyer H, Pratt D, Davis JL, Huges MS, Heller T, ElGindi M, Uppala A, Korangy F, Kliener DE, et al. Tremelimumab in combination with ablation in patients with advanced hepatocellular carcinoma. J Hepatol. 2017; 66:545-51.

68. Rahbari NN, Garden OJ, Padbury R, Brooke-Smith M, Crawford M, Adam R, Koch M, Makuuchi M, Dematteo RP, Christophi C, Banting S, Usatoff V, Nagino M, et al. Posthepatectomy liver failure: a definition and grading by the International Study Group of Liver Surgery (ISGLS). Surgery. United States; 2011 May; 149:713-24. 